\title{
Commercial yogurts as inoculum in yogurt making and their reusability properties
}

\author{
Oğuz Aydemir
}

Cite this article as:

Aydemir, O. (2020). Commercial yogurts as inoculum in yogurt making and their reusability properties. Food and Health, 6(4), $213-224$. https://doi.org/10.3153/FH20022

Çankırı Karatekin University,

Faculty of Engineering, Department of

Food Engineering, Çankırı, Turkey

ORCID IDs of the authors:

O.A. 0000-0003-0538-2311

Submitted: 13.02 .2020

Revision requested: 31.03 .2020

Last revision received: 02.04 .2020

Accepted: 21.04 .2020

Published online: 17.07 .2020

Correspondence: Oğuz AYDEMIR

E-mail: oaydemir@karatekin.edu.tr

\begin{abstract}
In Turkey, the habit of making their own yogurt in people's homes is quite common. Some of these people stated that when they used commercial yogurt as inoculum during the yogurt making, they could not achieve the product with desired properties. This research aims to investigate the possibility of using the commercial yogurts as an inoculum source in yogurt manufacturing. For this purpose, four different yogurts were produced by using four different commercial yogurts as a first inoculum separately. The yogurt production was repeated four times by using the last yogurts obtained as an inoculum. The effect of 4-generation yogurt production on some quality characteristics of yogurt was investigated. Moreover, first fermented yogurts were analyzed throughout 21day storage. Titratable acidity, $\mathrm{pH}$, serum separation, viscosity, and Lactobacillus delbrueckii subsp. bulgaricus and Streptococcus thermophilus counts were analyzed. The technological parameters in four yogurt generations did not show a significant change. In this context, it was concluded that the use of commercial yogurts as the first inoculum did not adversely affect the subsequent fermentation process when the necessary hygienic and temperature conditions were maintained.
\end{abstract}

Keywords: Yogurt making, Commercial yogurts, Inoculum, Technological characteristics

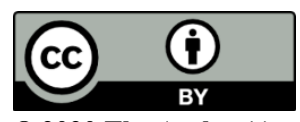

(c) 2020 The Author(s)

Available online at

http://jfhs.scientificwebjournals.com 


\section{Introduction}

Yogurt making dates back to many centuries, although there is no accurate record of the date when it was first made. According to the legend, yogurt was first made by the ancient Turkish people in Asia (Tarakçı, 2010). For thousands of years, yogurt has been popular fermented milk in the Middle East and, for the most part, the product was made in individual households or on a limited communal scale (Robinson, $2002 \mathrm{~b}$ ). Both historically and commercially, yogurt is the most popular product made with thermophilic cultures, and a typical commercial sample will contain millions of viable cells of Streptococcus salivarius subsp. thermophilus and Lactobacillus delbrueckii subsp. bulgaricus (Robinson, 2002a). The gel structure of yogurt results primarily from acid effect, which was created by these bacteria, on the integrity of the casein micelle (Rawson and Marshall, 1997).

At present, the retail markets of many countries are dominated by two types of yogurt. One type has a firm, gel-like structure together with a clean, mildly acidic and slightly aromatic flavour - 'natural set yogurt', while the other has the consistency of 'double cream' and the taste and aroma of yogurt is usually modified by the addition of fruit/favours and sugar - 'stirred yogurt' (Robinson, 2002a). Set type yogurt is more popular in Turkish market. People in Turkey still continue to make yogurt in their own homes. For this purpose, they can make yogurt using the same yogurt repeatedly. Also, when people do not have yogurts, they may request yogurt to use as inoculum from their neighbours. People who cannot find homemade yogurt as inoculum can also use commercial yogurts or cultures for this purpose. Recently, some consumers have complained that the quality of yogurts produced from commercial yogurts is not at the desired level. The problems are watery/weak texture and ropiness in structure. The aim of this study is to investigate the suitability of commercial yogurts as inoculum for yogurt production. Four different yogurt companies with the highest market share in Turkey was selected as the material. The yogurt was produced by the use of these commercial yogurts as the first inoculum. $\mathrm{pH}$, titratable acidity, serum separation, viscosity values and $L b$. delbrueckii subsp. bulgaricus and S. salivarius subsp. thermophilus counts in yogurts obtained by fermenting four times in succession and in yogurts stored at $4^{\circ} \mathrm{C}$ for 21 days were determined.

\section{Materials and Methods}

Four commercial yogurt samples (A, B, C and D) were supplied from the local market in Çankırı (Turkey) for this study in April-2016. UHT milk which contains 3.1\% fat, 2.8\% protein, $4.7 \%$ lactose (Dost, Ak Gida, Turkey) was used for yogurt production.

\section{Production of Yogurt}

$330 \mathrm{~mL}$ glass jars with metal lid were wrapped in aluminum foil and sterilized for $150 \mathrm{~min}$ at $170{ }^{\circ} \mathrm{C}$. $200 \mathrm{~mL}$ of UHT milks, which were kept in $45{ }^{\circ} \mathrm{C}$ water bath for 1 hour in a packaged state, were transferred into sterile jars under aseptic conditions. $4 \mathrm{~g}(2 \%)$ of the commercial yogurts as inoculum source were added to the milk and mixed. They were incubated at $43 \pm 0.5^{\circ} \mathrm{C}$ until $\mathrm{pH}$ was below 4.6 and then taken to the refrigerator at $4{ }^{\circ} \mathrm{C}$. The next yogurt production was carried out using a 24-hour yogurt sample. Thus, 4 generation of yogurt productions were consecutively performed. In addition, first generation yogurts were stored in the refrigerator for 21 days and analyzed for the same parameters on the 1st, 7 th, 14th and 21st days of storage. Two replicates of yogurt production were performed.

\section{Analytical Methods}

The $\mathrm{pH}$ was measured through a $\mathrm{pH}$ meter (Ohaus, ST3100, Switzerland) on yogurt directly. The titratable acidity was determined as lactic acid percentage by titrating with $0.1 \mathrm{~N}$ $\mathrm{NaOH}$, using phenolphthalein as an indicator. Viscosity measurement on stirred yogurt samples was performed under room temperature $\left(23 \pm 2{ }^{\circ} \mathrm{C}\right)$ using a Brookfield DV2T Viscometer (Brookfield Engineering Laboratories, Inc., Middleboro, MA), equipped with a No. 3 spindle running at $15 \mathrm{rpm}$. Viscosity readings were carried out at the point of the 30th second. Syneresis of the yogurt samples were measured by the centrifugation. Yogurt (40 g) was weighed in centrifuge tubes and centrifuged at $2500 \mathrm{rpm}$ for $10 \mathrm{~min}$ at $4{ }^{\circ} \mathrm{C}$. The supernatant was separated, weighed and syneresis was calculated according to the following equation (Farnsworth et al., 2006):

Syneresis $(\%)=\frac{\text { weight of supernatant }(\mathrm{g})}{\text { weight of yogurt sample }(\mathrm{g})} \times 100$

\section{Microbiological Analyses}

Ten gram yogurt sample was mixed with $90 \mathrm{~mL}$ of $1 / 4$ Ringer solution (Merck, Germany) and homogenized uniformly with a stomacher (BagMixer 400, Interscience, France). Subsequent serial dilutions were prepared and microbial numbers determined using pour plate technique. S. salivarius subsp. thermnophilus counts were enumerated on ST agar (HiMedia, India) aerobically at $37^{\circ} \mathrm{C}$ for $72 \mathrm{~h}$. MRS agar (Merck, Germany) was used for the enumeration of Lb. delbrueckii subsp. bulgaricus at $43^{\circ} \mathrm{C}$ for 5 days (Dave and Shah, 1997). 


\section{Results and Discussion}

\section{Analytical Characteristics}

The $\mathrm{pH}$ profile of yogurt samples during the incubation period in 4 generations is shown in Figure 1. Except for the D sample, the slowest decrease in the $\mathrm{pH}$ between the generations was obtained in the first generation yogurt. This period lasted 210 minutes in samples A and B, 240 minutes in sample $C$ and 180 minutes in sample D. In all samples, fermentations of the next 2nd, 3rd and 4th generation yogurts were completed in 180 minutes. Only the long incubation time of the first generation yogurt may be due to the adaptation of the culture to the new milk and waiting time of the commercial yogurts in the groceries' shelves. There was no difference between the incubation times of the $2 \mathrm{nd}$, 3rd and 4th generation yogurts $(\mathrm{P}>0.05)$. The difference among the samples was significant $(\mathrm{P}<0.05)$. The highest $\mathrm{pH}$ value was found in the sample $\mathrm{C}$ and the lowest was observed in the sample A $(\mathrm{P}<0.05)$. Robinson et al. (2006) stated that decreasing to the isoelectric point of caseins $(\mathrm{pH} 4.6)$ and increasing to the level of $1.0-1.2 \%(\mathrm{w} / \mathrm{v})$ titratable acidity took in 3-4 hours. Mohammadi et al. (2011) and De Brabandere and De Baerdemaeker (1999) determined that incubation time was 190 min and 3-3.5 hours, respectively.

Figure 2 shows the change in the $\mathrm{pH}$ of the 1st generation yogurt samples during the 21-day storage period. There was a rapid decrease in $\mathrm{pH}$ until the 7th day and the $\mathrm{pH}$ tended to remain constant after the 7 th day. Considering the mean values during storage, the highest $\mathrm{pH}$ was observed in yogurt $\mathrm{C}$, while the lowest $\mathrm{pH}$ was determined in yogurt $\mathrm{A}(\mathrm{P}<0.05)$. $\mathrm{B}$ and $\mathrm{D}$ yogurts showed similar $\mathrm{pH}$ values $(\mathrm{P}>0.05)$. GülerAkın (2005), Tarakci et al. (2010) and Dabrowska et al. (2017) found similar results for $\mathrm{pH}$ in different yogurt samples.
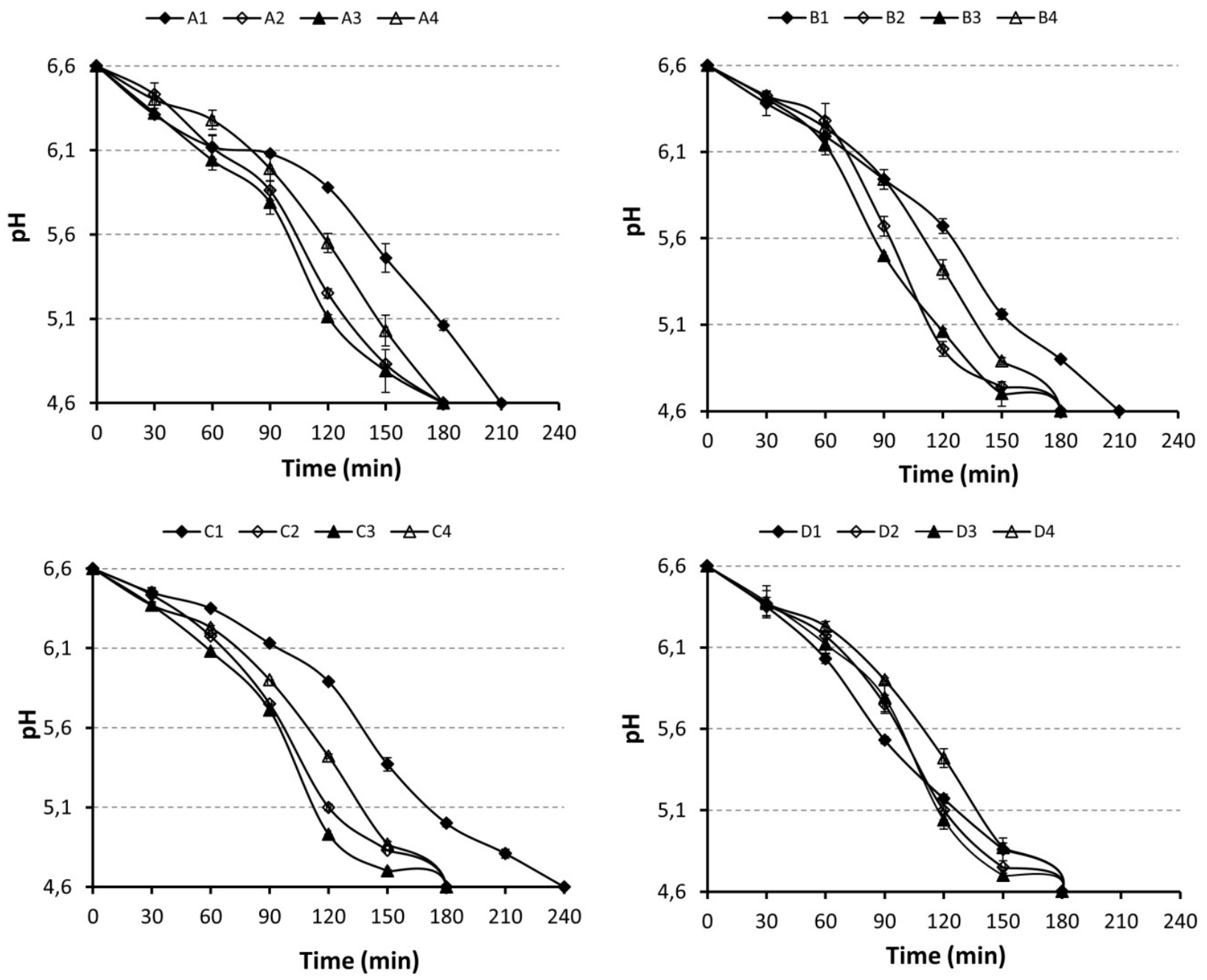

Figure 1. $\mathrm{pH}$ profil of generations in yogurt samples 


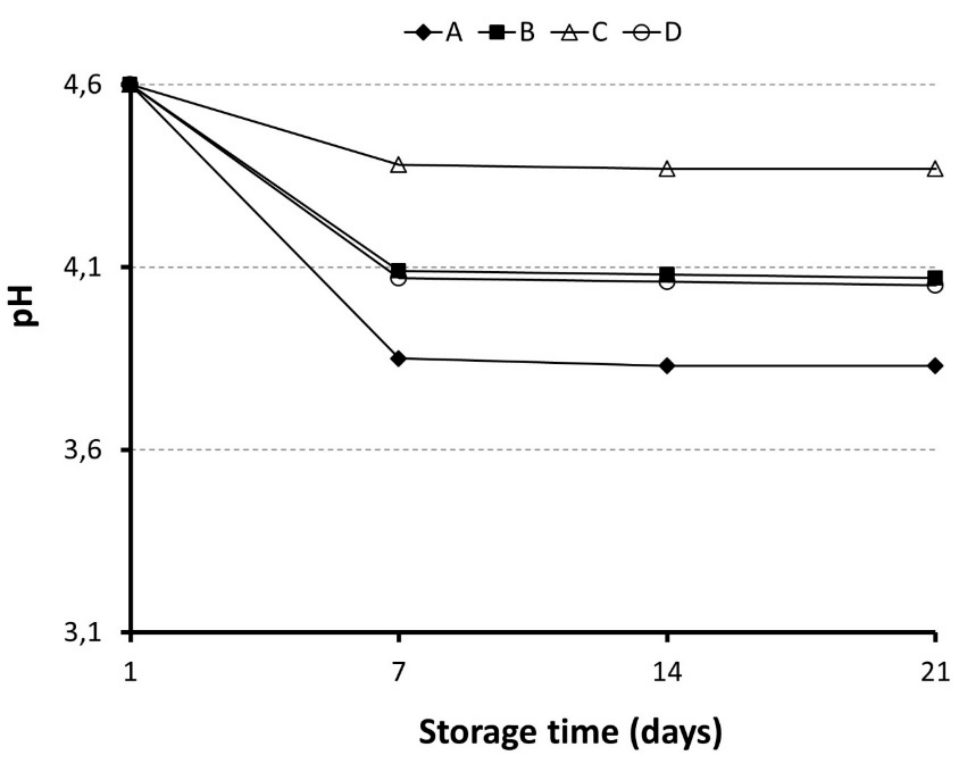

Figure 2. $\mathrm{pH}$ in yogurts during cold storage

Titratable acidity values in the 4 generations of samples are presented in Figure 3. While the differences among the generations were not significant $(\mathrm{P}>0.05)$, there was a significant difference among the mean titratable acidity values of the samples $(\mathrm{P}<0.05)$. Titratable acidity values ranged from 0.69 to $0.92 \%$ among the generations. The highest mean titratable acidity values were observed in the sample A, the lowest titratable acidity was determined in the sample $\mathrm{C}(\mathrm{P}<0.05)$. It was observed that these titratable acidity values were compatible with $\mathrm{pH}$ values. Similar titratable acidity values were obtained by Güler-Akın (2005) and Tarakci et al. (2010).

The titratable acidity change of the 1st generation yogurt samples during 21 days of storage is shown in Figure 4. As the storage period progressed, the titratable acidity values of the yogurts increased slightly. Considering the mean values during storage, the highest titratable acidity was found in yogurt A, while the lowest acidity values were detected in C. B and $\mathrm{D}$ yogurts presented similar acidity values. For titratable acidity, Güler-Akın (2005), Mudawi et al. (2014), Ramchandran and Shah (2010) Joung et al. (2016) found similar results during storage.

The viscosity values of yogurt samples are given in Figure 5. While the differences among the generations were significant $(\mathrm{P}<0.05)$, the difference among the mean viscosity values of the samples was found to be not significant $(\mathrm{P}>0.05)$. Viscosity values in samples ranged from 2374 (sample C) to 3153 (sample B) cP among the generations. The highest mean viscosity values were observed in the sample $B$, the lowest viscosity was determined in the sample A. Bacterial culture compositions or specific strains, especially those releasing exopolysaccharides or containing probiotics, take an active role in the forming of yogurt texture (Espirito-Santo et al., 2013). While the first generation production gave the lowest viscosity $(\mathrm{P}<0.05)$, no significant difference was observed among the other 2 nd, 3 rd and 4 th generations. This may be related to the process of adaptation of starter bacteria to the new milk environment in the first generation production. Tarakci et al. (2010) found similar results for viscosity in different yogurt samples.

The viscosity values of the 1st generation yogurt samples during the storage are shown in Figure 6 . The viscosity values of the yogurts increased till the 7th day. After the 7th day, viscosity decreased slightly. However, the viscosity values in the 1th day were similar to the values in the end of storage. Considering the mean values during storage, yogurts $\mathrm{B}$ and $\mathrm{C}$ showed higher viscosity than yogurts $\mathrm{A}$ and $\mathrm{D}(\mathrm{P}<0.05)$. Krisnaningsih et al. (2019) found similar results for viscosity in yogurt samples during storage.

Syneresis values in the 4 generations of samples are presented in Figure 7. While the differences among the generations were significant $(\mathrm{P}<0.05)$, there was no significant difference among the mean syneresis values of the samples $(\mathrm{P}>0.05)$. Syneresis values ranged from 18.36 (Sample B) to $27.78 \%$ (sample D) among the generations. The syneresis value of the 4 th generation yogurts was significantly lower $(\mathrm{P}<0.05)$. While Güler-Akın, (2005), Farnsworth et al. (2006) and Abbasi et al. (2009) determined lower syneresis than those of the present study depending on the total solids contents, heat treatment conditions, and presence of additives. 


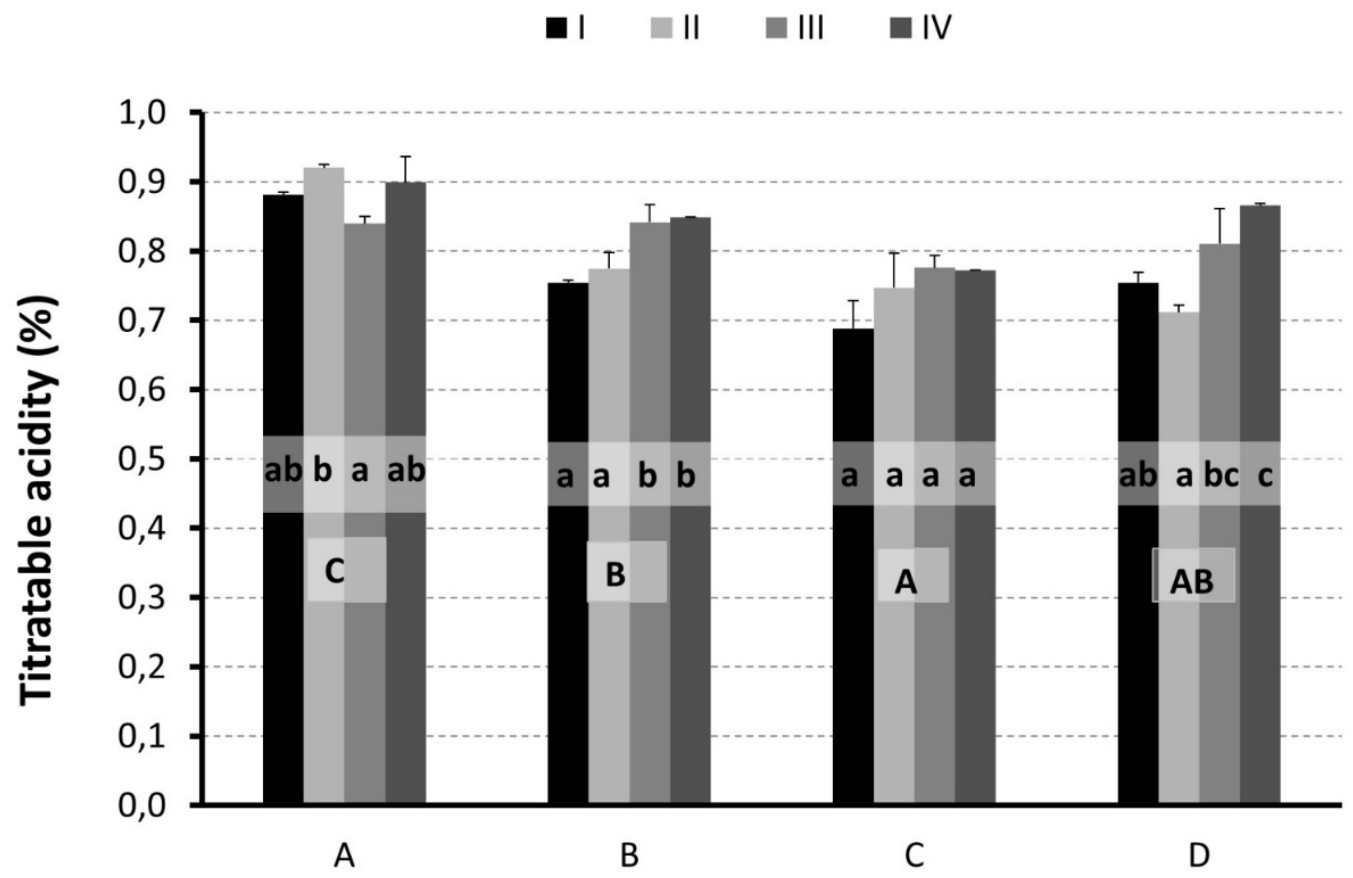

Yogurt samples

A-C: Means with same letters in a row within the category for samples are not significant at $\mathrm{P}>0.05$ ${ }^{a-c}$ : Means with same letters in a row within the sample for generations are not significant at $P>0.05$

Figure 3. Titratable acidity changes in yogurt samples.

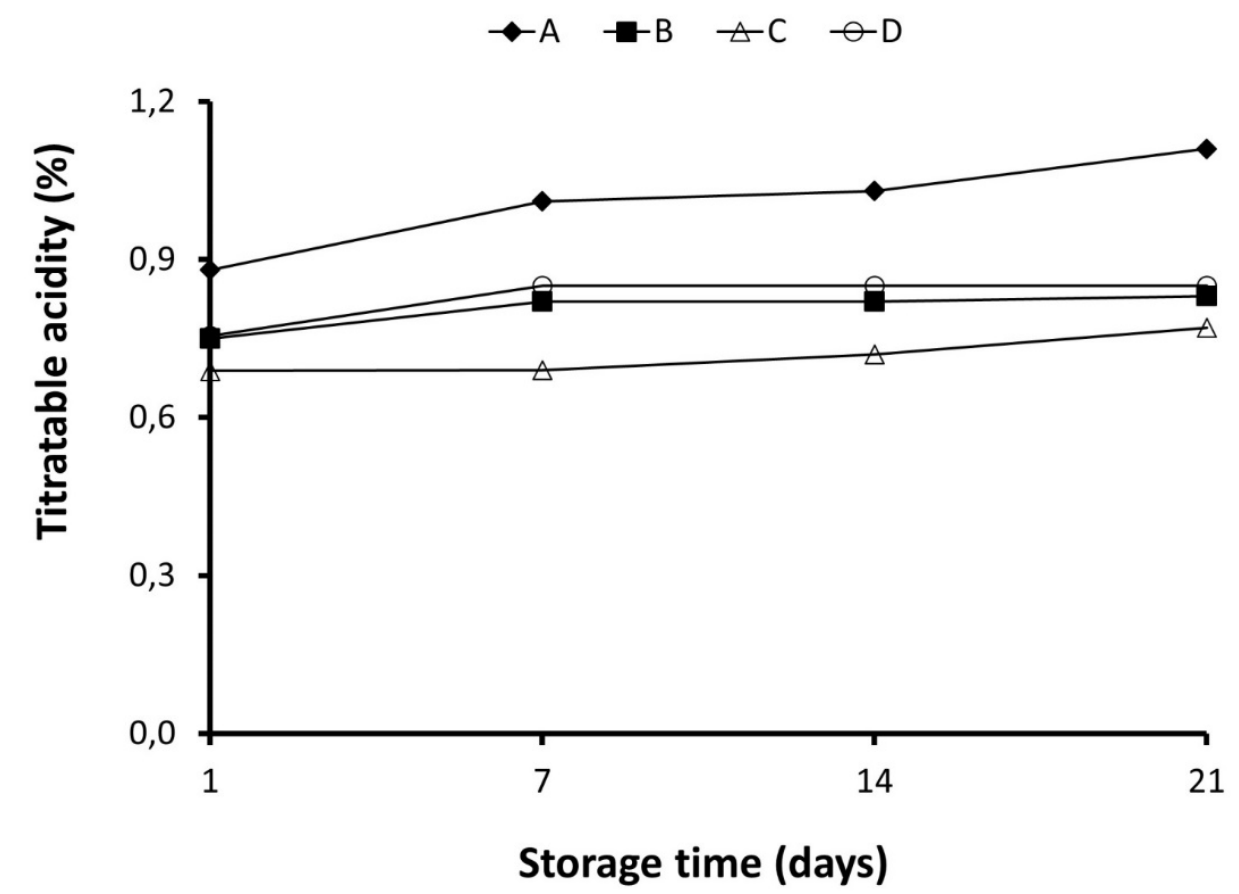

Figure 4. Titratable acidity in yogurts during cold storage 


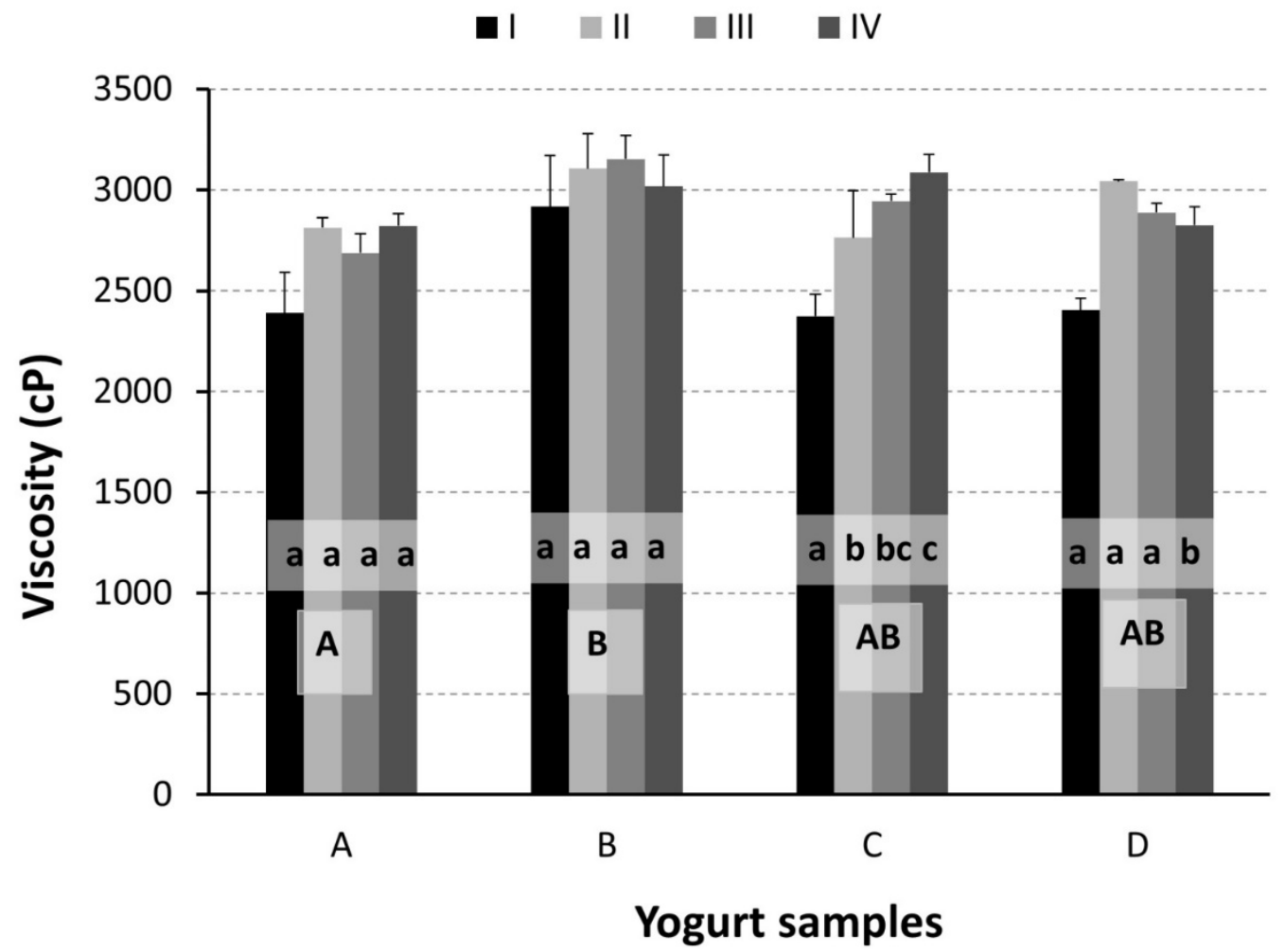

${ }^{A-C}$ : Means with same letters in a row within the category for samples are not significant at $\mathrm{P}>0.05$ ${ }^{\mathrm{a}-\mathrm{c}}$ : Means with same letters in a row within the sample for generations are not significant at $\mathrm{P}>0.05$

Figure 5. Viscosity values in yogurt samples

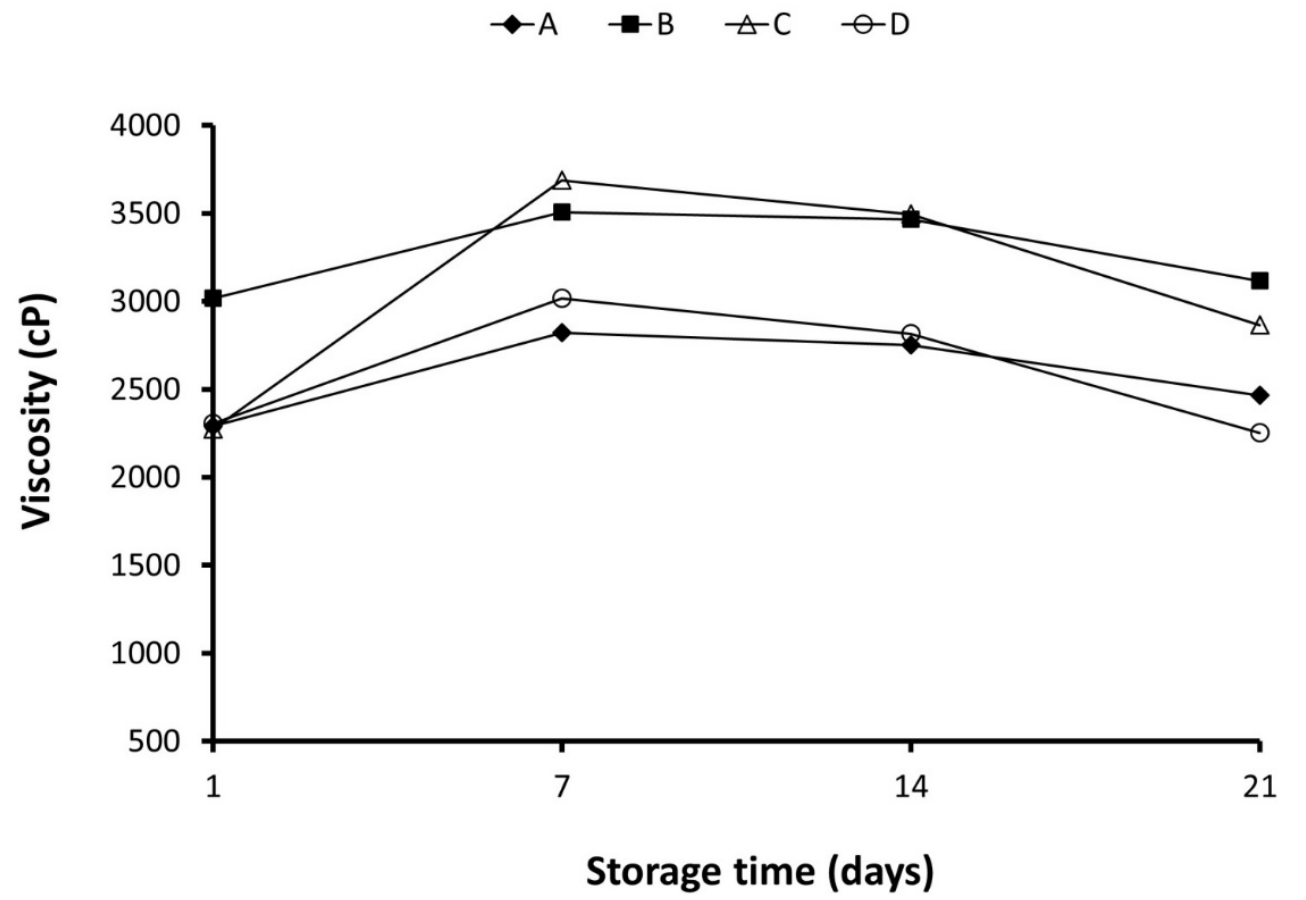

Figure 6. Viscosity in yogurts during cold storage 


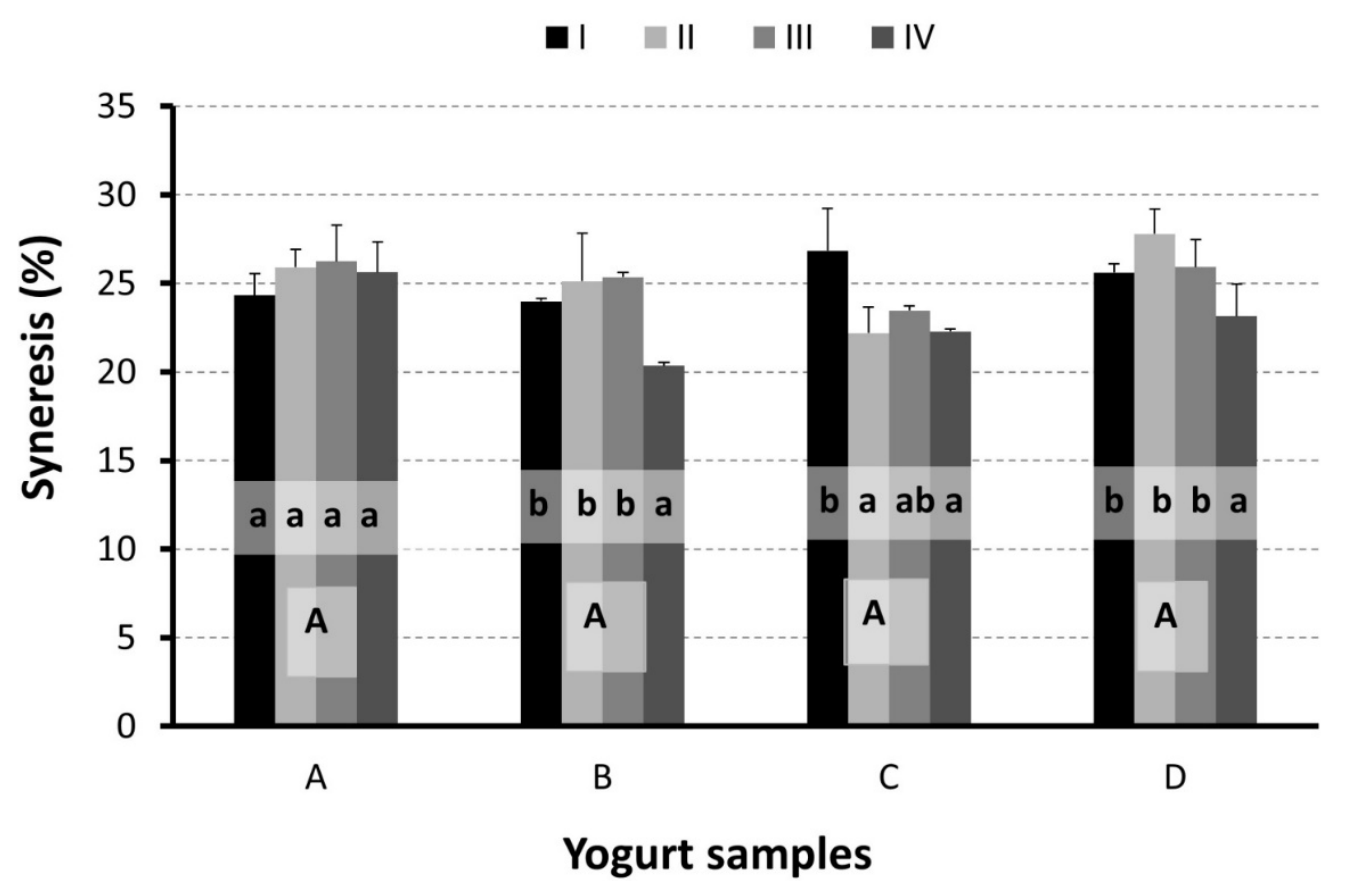

A: Means with same letters in a row within the category for samples are not significant at $\mathrm{P}>0.05$

$\mathrm{a}-\mathrm{b}$ : Means with same letters in a row within the sample for generations are not significant at $\mathrm{P}>0.05$

Figure 7. Syneresis values in yogurt samples

The profile of syneresis values of 1 st generation yogurt samples during storage is shown in Figure 8. In general, syneresis values tended to remain constant during storage. Considering the mean values during storage, there was no significant difference among the yogurt sample $(\mathrm{P}>0.05)$. While GülerAkın (2005) and Tarakci et al. (2010) found a decrease in syneresis during storage, Mudawi et al. (2014) observed an increase in whey separation.

It is normal for yogurts produced by using commercial yogurts as inoculum in home conditions to be different from commercial yogurts in terms of structure and texture. Because milk is standardized, homogenized and evaporated in the production of commercial yogurts. The consistency of the yogurt produced at home using commercial yogurt will not be the same with original commercial yogurt. Yogurt produced at home will be relatively weaker.

\section{Evaluation of Microbiological Counts}

Lb. delbrueckii subsp. bulgaricus counts in the 4 generations of samples are shown in Figure 9. While the differences among the generations were not significant $(\mathrm{P}>0.05)$, there was a significant difference among the mean $L b$. delbrueckii subsp. bulgaricus counts of the samples $(\mathrm{P}<0.05)$. Lb. delbrueckii subsp. bulgaricus counts ranged from 4.25 (sample
C) to 9.28 (sample A) $\log$ cfu g $^{-1}$ among the generations. The highest mean $L b$. delbrueckii subsp. bulgaricus counts were observed in the sample A, the lowest counts were determined in the sample $\mathrm{C}(\mathrm{P}<0.05)$. It was observed that these $L b$. delbrueckii subsp. bulgaricus counts were compatible with titratable acidity $\mathrm{pH}$ values. Some authors reported similar $L b$. delbrueckii subsp. bulgaricus results with yogurts A, B and D (Miller et al., 2002; Güler-Akın, 2005; Asensio-Vegas, et al., 2018). As in the $C$ sample, there are also a few studies reporting a low Lb. delbrueckii subsp. bulgaricus counts (Dave and Shah, 1997; Lopes et al., 2019).

The Lb. delbrueckii subsp. bulgaricus counts of 1st generation yogurt samples during the storage are shown in Figure 10. The Lb. delbrueckii subsp. bulgaricus counts of the yogurts tended to decrease during storage. With the exception of the $\mathrm{C}$ sample showing the lowest Lb. delbrueckii subsp. bulgaricus counts $(\mathrm{P}<0.05)$, the bacteria counts in the samples during storage slightly decreased. Considering the mean values during storage, yogurts $\mathrm{A}, \mathrm{B}$ and $\mathrm{D}$ showed similar counts ( $\mathrm{P}>0.05)$. Güler-Akın (2005) and Asensio-Vegas, et al. (2018) found that $L b$. delbrueckii subsp. bulgaricus counts decreased slightly during storage. 


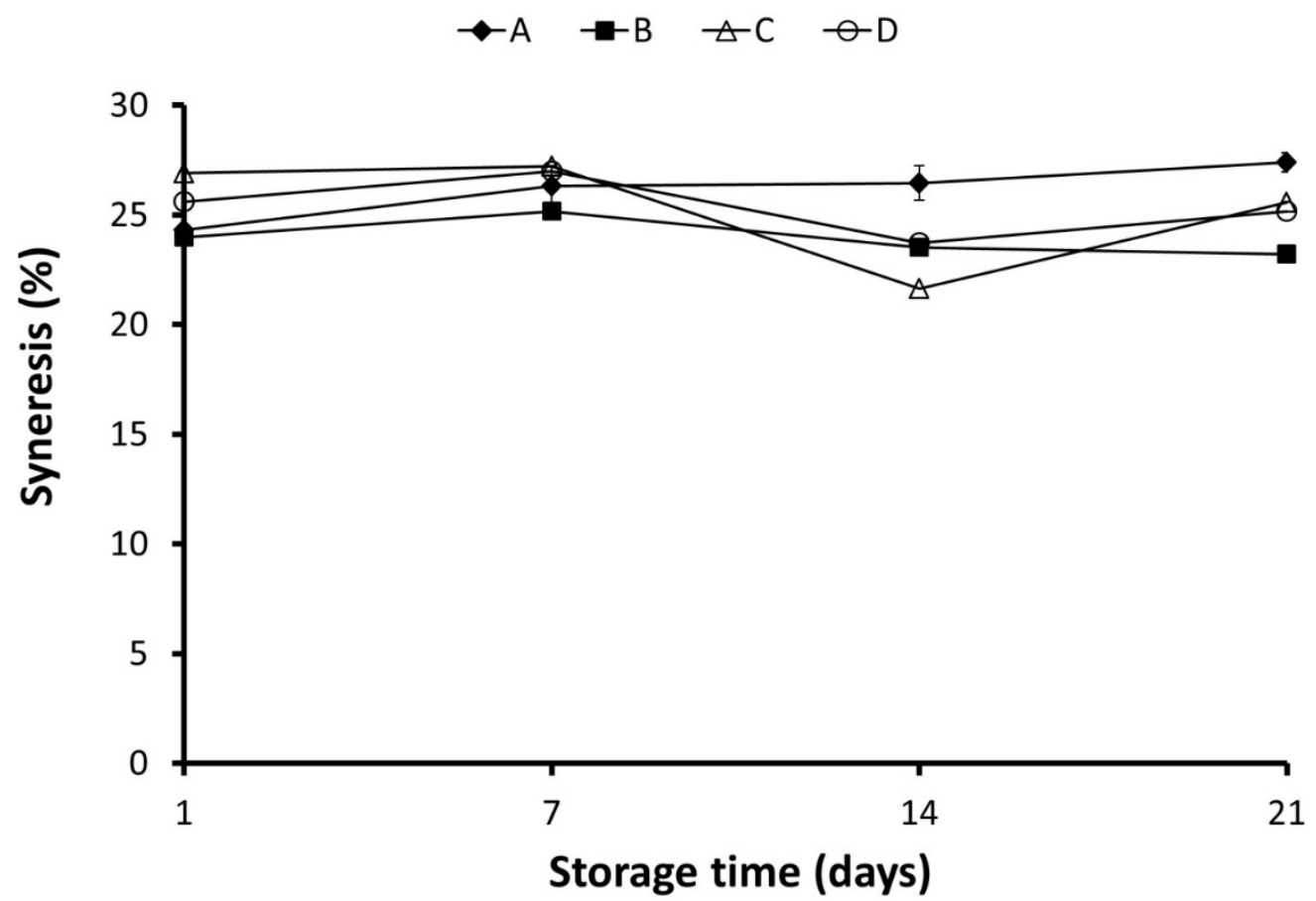

Figure 8. Syneresis in yogurts during cold storage

- I II $\square$ III $\square I V$

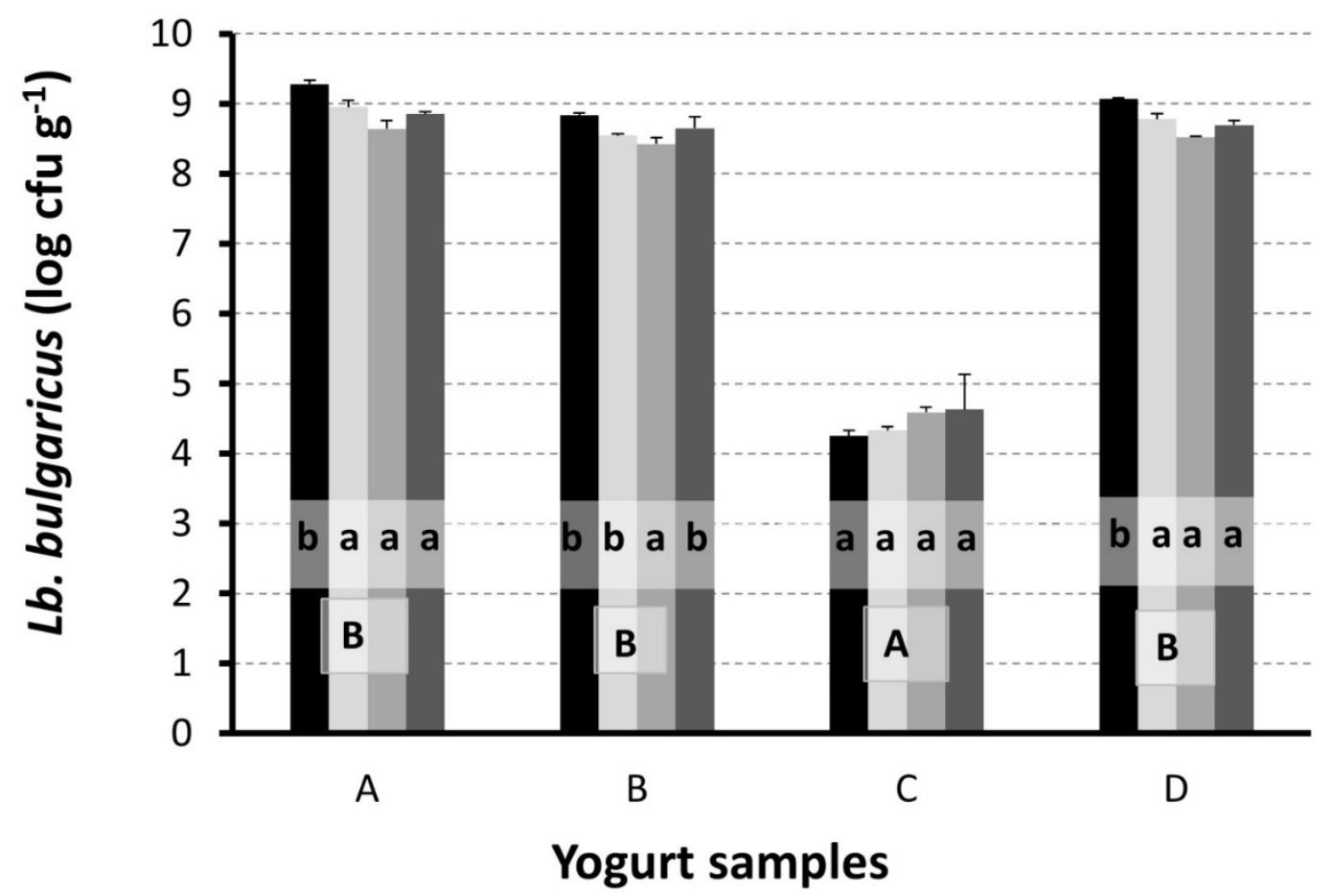

A-B: Means with same letters in a row within the category for samples are not significant at $\mathrm{P}>0.05$

${ }^{\mathrm{a}-\mathrm{b}}$ : Means with same letters in a row within the sample for generations are not significant at $\mathrm{P}>0.05$

Figure 9. Lb. delbrueckii subsp. bulgaricus counts in yogurt samples 


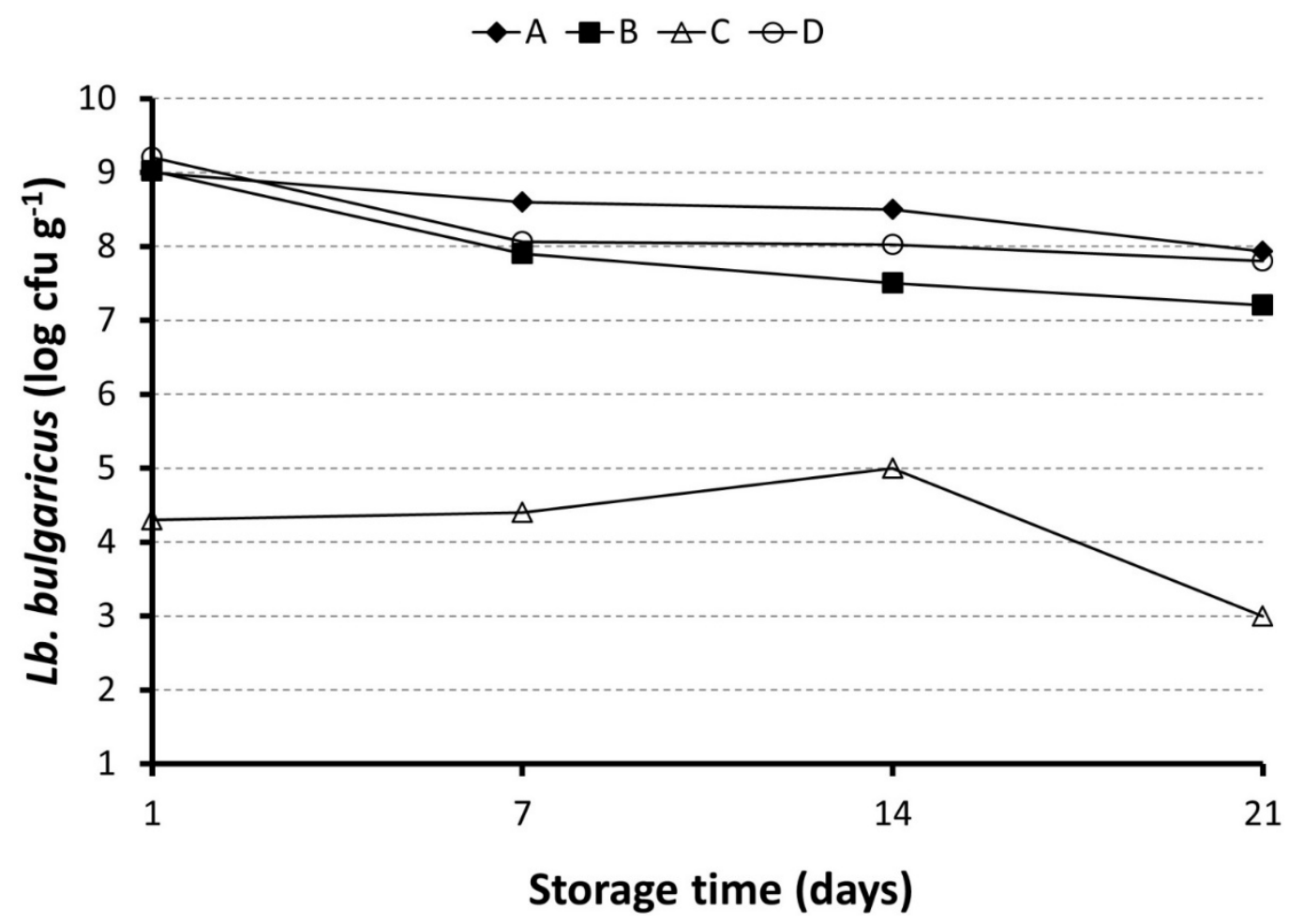

Figure 10. Lb. delbrueckii subsp. bulgaricus in yogurts during cold storage

S. salivarius subsp. thermophilus counts in the 4 generations of samples are presented in Figure 11. While the differences among the samples were not significant $(\mathrm{P}>0.05)$, there was a significant difference among the $S$. salivarius subsp. thermophilus counts of the generations $(\mathrm{P}<0.05)$. S. salivarius subsp. thermophilus counts ranged from 8.01 (sample C) to 9.09 (sample D) $\log \mathrm{cfu} \mathrm{g}^{-1}$ among the generations. The highest mean $S$. salivarius subsp. thermophilus counts were observed in the sample A, the lowest counts were determined in the sample C. Miller et al., 2002 and Lopes et al., (2019) found similar results for $S$. salivarius subsp. thermophilus in yogurts.

S. salivarius subsp. thermophilus counts in 1st generation yogurt samples during the storage are presented in Figure 12. S. salivarius subsp. thermophilus counts of the yogurts increased till the 7th day. After 7th day, bacteria counts remained constant except sample A showed a slight decrease.
Considering the mean values during storage, there was no significant difference among the yogurt sample $(\mathrm{P}>0.05)$. Some authors reported similar $S$. salivarius subsp. thermophilus results and trend (Dave and Shah, 1997; Güler-Akın, 2005; Asensio-Vegas, et al., 2018).

Another reason why the yogurts produced by using commercial yogurts as inoculum in home conditions are different from the commercial yogurts in terms of structure and texture is that the required constant incubation temperature and the necessary hygienic conditions are not achieved in the home conditions. In addition, the hygienic condition (microflora) of the yogurt used as inoculum and the survival rates of the starter culture in this yogurt are of great importance. Of course, the characteristics of the strains in starter culture are very important in yogurt making. 
$\square I \square$ II $\square$ III $\square$ IV

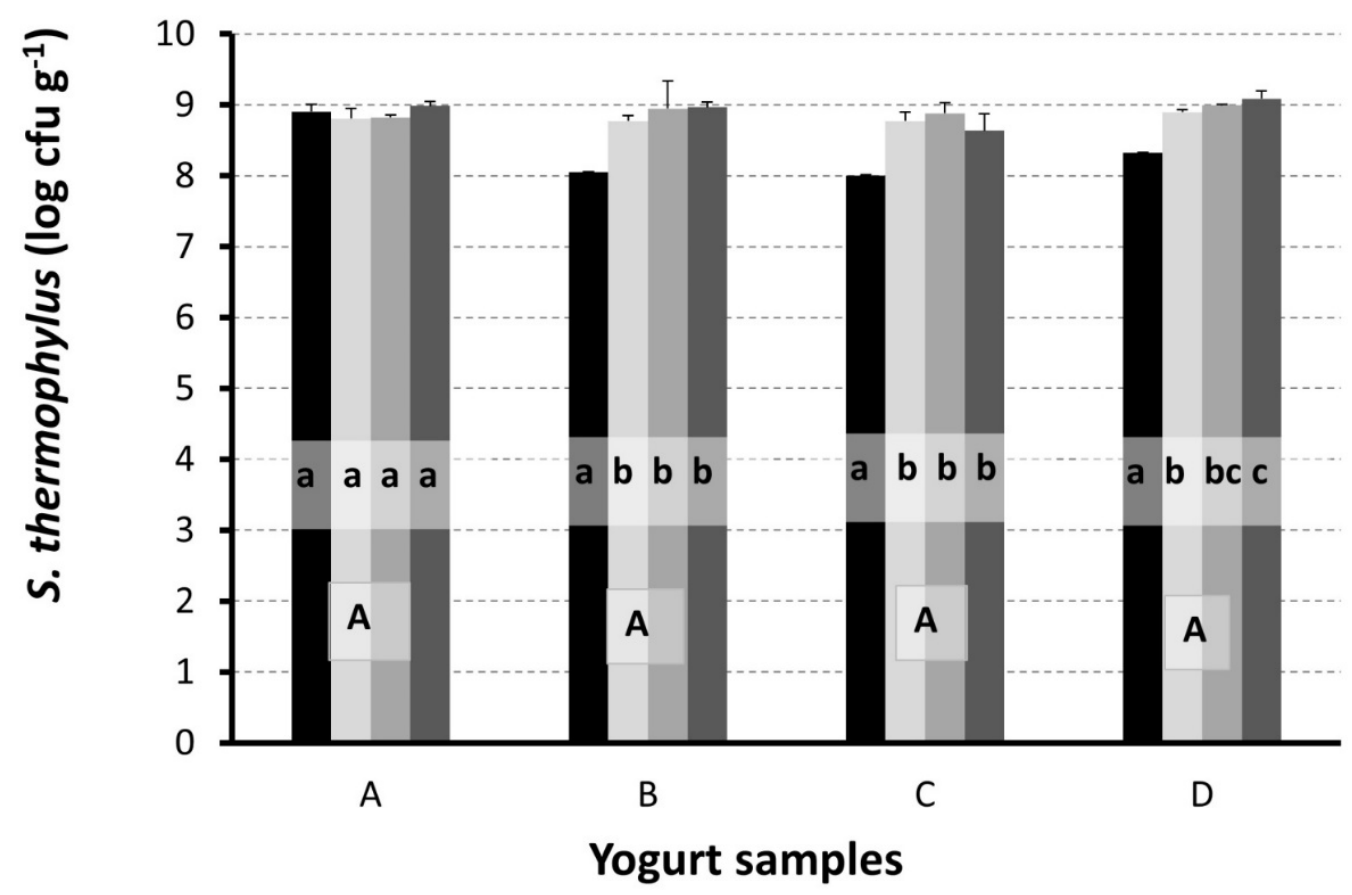

A: Means with same letters in a row within the category for samples are not significant at $\mathrm{P}>0.05$ ${ }^{\mathrm{a}-\mathrm{c}}$ : Means with same letters in a row within the sample for generations are not significant at $\mathrm{P}>0.05$

Figure 11. S. salivarius subsp. thermophilus counts in yogurt samples

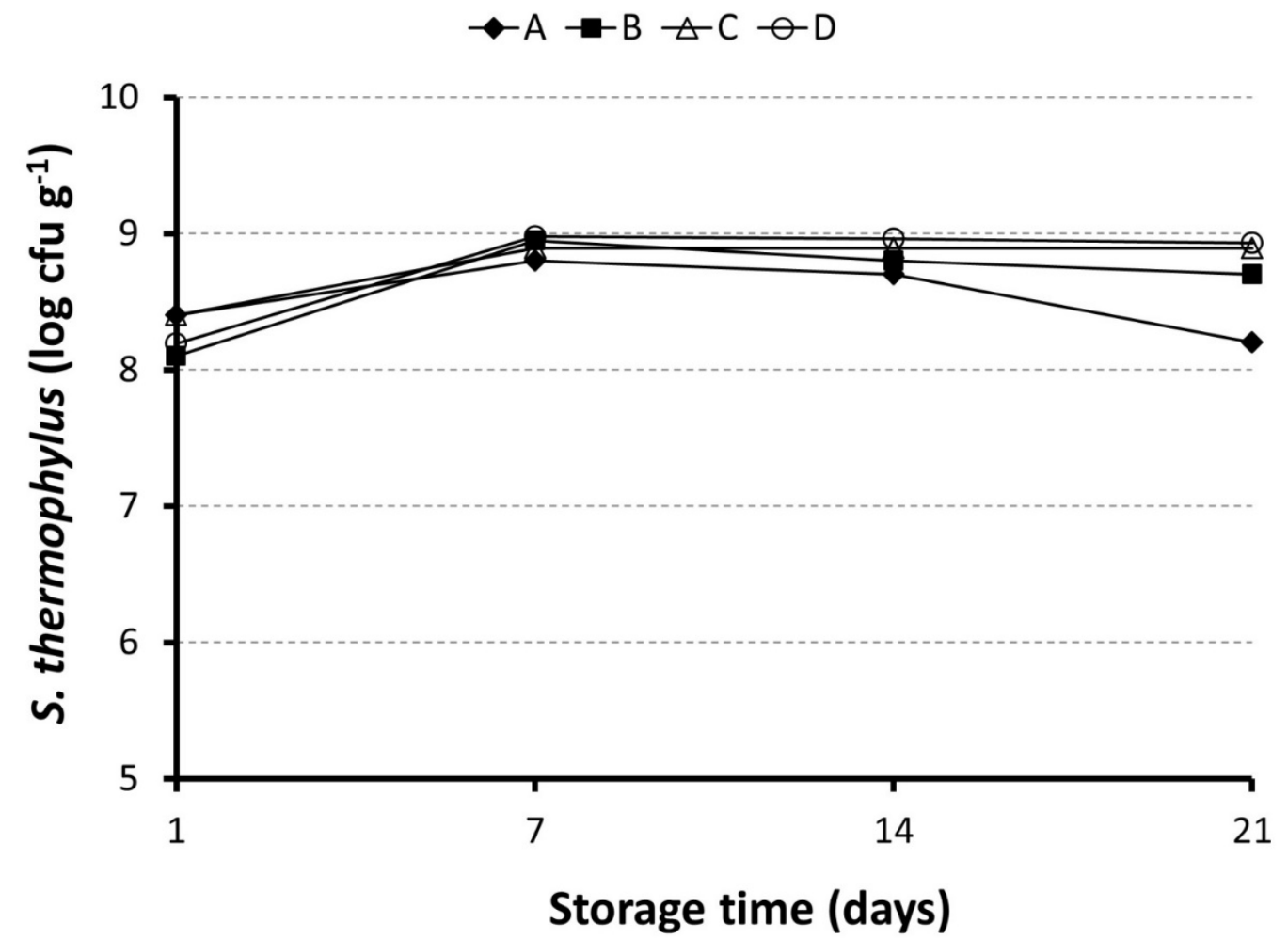

Figure 12. S. salivarius subsp. thermophilus in yogurts during cold storage 


\section{Conclusions}

In this study, it was investigated whether it is possible to make yogurt by using commercial yogurts as starter culture and as a result, it is observed that this is possible if the necessary hygienic conditions and incubation temperature are paid attention. Since these two conditions cannot be followed very well in the home environment and also the shelf life and hygienic quality of the yogurt that will be used as the source of inoculation cannot be standard, home yogurts cannot be expected to be of standard quality. In order to better illuminate yogurt inoculation and fermentation, studies on yogurt making processes where yogurt stored during different times can be used as the source of inoculation may be beneficial.

\section{Compliance with Ethical Standard}

Conflict of interests: The authors declare that for this article they have no actual, potential or perceived the conflict of interests.

Ethics committee approval: Author declare that this study does not include any experiments with human or animal subjects.

Funding disclosure: -

Acknowledgments: The author would like to thank Filiz Ezer, Fatma Uysal, Emine Ademi and Seda Özkan for their help. The author is also grateful to Çankırı Karatekin University Faculty of Engineering.

Disclosure: A part of this research was presented as oral and published in abstract form at the 2nd International Eurasian Conference on Biological and Chemical Sciences (EurasianBioChem 2019), 28-29 June 2019, Ankara, Turkey.

\section{References}

Abbasi, H., Mousavi, M.E., Ehsani, M.R., D-Jomea, Z.E., Vaziri, M. Rahimi J., Aziznia, S. (2009). Influence of starter culture type and incubation temperatures on rheology and microstructure of low fat set yoghurt. International Journal of Dairy Technology, 62(4), 550-555.

https://doi.org/10.1111/j.1471-0307.2009.00513.x

Asensio-Vegas, C., Tiwari, B., Gredilla, A.E., Bueno, F., Delgado, D., Martin-Diana, A.B. (2018). Development of yoghurt from ovine milk with enhanced texture and flavour properties. International Journal of Dairy Technology, 71(1), 112-121.

https://doi.org/10.1111/1471-0307.12341
Dabrowska, A., Babij, K., Szołtysik, M., Chrzanowska J. (2017). Viability and growth promotion of starter and probiotic bacteria in yogurt supplemented with whey protein hydrolysate during refrigerated storage. Advances in Hygiene \& Experimental Medicine, 71, 952-959.

https://doi.org/0.5604/01.3001.0010.5866

Dave, R.I., Shah, N.P. (1997). Viability of yoghurt and probiotic bacteria in yoghurts made from commercial starter cultures. International Dairy Journal, 7, 31-41.

https://doi.org/10.1016/S0958-6946(96)00046-5

De Brabandere, A.G., De Baerdemaeker, J.G. (1999). Effects of process conditions on the $\mathrm{pH}$ development during yogurt fermentation. Journal of Food Engineering, 41, 221-227. https://doi.org/10.1016/S0260-8774(99)00096-5

Espirito-Santo, A.P., Lagazzo, A., Sousa, A.L.O.P., Perego, P., Converti, A., Oliveria, M.N. (2013). Rheology, spontaneous whey separation, microstructure and sensorial characteristics of probiotic yoghurts enriched with passion fruit fiber. Food Research International, 50, 224-231.

https://doi.org/10.1016/j.foodres.2012.09.012

Farnsworth, J.P., Li, J., Hendricks, G.M., Guo, M.R. (2006). Effects of transglutaminase treatment on functional properties and probiotic culture survivability of goat milk yogurt. Small Ruminant Research, 65, 113-121.

https://doi.org/10.1016/j.smallrumres.2005.05.036

Güler-Akın, M.B. (2005). The effects of different incubation temperatures on the acetaldehyde content and viable bacteria counts of bio-yogurt made from ewe's milk. International Journal of Dairy Technology, 58(3), 174-179.

https://doi.org/10.1111/j.1471-0307.2005.00209.x

Joung, J.Y., Lee, J.Y., Ha, Y.S., Shin Y.K., Kim, Y., Oh, N.S., (2016). Enhanced Microbial, Functional and Sensory Properties of Herbal Yogurt Fermented with Korean Traditional Plant Extracts. Korean Journal of Food Science and Animal Resource, 36(1), 90-99.

https://doi.org/10.5851/kosfa.2016.36.1.90

Krisnaningsih, A., Radiati , I., Evanuarini, H., Rosyidi D. (2019). The effect of incubation time to the physicochemical and microbial properties of yoghurt with local taro (Colocasia esculenta (L.) Schott) starch as stabilizer. Current Research in Nutrition and Food Science, 7(2), 547-554.

https://doi.org/10.12944/CRNFSJ.7.2.23 
Lopes, R.P., Mota, M.J., Pinto, C.A., Sousa, S., Lopes da Silva, J.A., Gomes, A.M., Delgadillo, I., Saraiva, J.A. (2019). Physicochemical and microbial changes in yogurts produced under different pressure and temperature conditions. LWT - Food Science and Technology, 99, 423-430.

https://doi.org/10.1016/j.lwt.2018.09.074

Miller, D.M., Dudley, E.G., Roberts, R.F. (2002). Development of a quantitative PCR method for monitoring strain dynamics during yogurt manufacture. Journal of Dairy Science, 95 , 4868-4872.

https://doi.org/10.3168/jds.2012-5445

Mohammadi, R., Rouhi, M., Mortazavian, A.M. (2011). Effects of music waves on fermentation characteristics and viability of starter cultures in probiotic yogurt. Milchwissenschaft, 66(2), 193-196.

Mudawi, H.A., Abdelrahim, S.M.K and Mustafa, A.M.I. (2014). Effect of incubation and storage temperatures on quality of set yoghurt. Egyptian Academic Journal of Biological Sciences, 6(2), 131-137.

https://doi.org/10.21608/eajbsc.2014.16040

Ramchandran, L., Shah, N.P. (2010). Characterization of functional, biochemical and textural properties of symbiotic low-fat yogurts during refrigerated storage. LWT - Food Science and Technology, 43, 819-827.

https://doi.org/10.1016/j.lwt.2010.01.012

Rawson, H.L., Marshall, V.M. (1997). Effect of 'ropy' strains of Lactobacillus delbrueckii ssp. bulgaricus and Streptococcus thermophilus on rheology of stirred yogurt. International Journal of Food Science and Technology, 32(3), 213-220.

https://doi.org/10.1046/j.1365-2621.1997.00395.x

Robinson, R.K. (2002a). Fermented Milks/Yoghurt Types and Manufacture. In Encyclopedia of Dairy Sciences. H. Roginski (ed.) pp. 1055-1058, London, UK, Academic Press. ISBN 978-0-12-227235-6 https://doi.org/10.1016/B0-12-227235-8/00171-1

Robinson, R.K. (2002b). Fermented Milks/ Yoghurt, Role of Starter Cultures. In Encyclopedia of Dairy Sciences. H. Roginski (ed.) pp. 1059-1063, London, UK, Academic Press. ISBN 978-0-12-227235-6

https://doi.org/10.1016/B0-12-227235-8/00172-3

Robinson, R.K., Lucey, J.A., Tamime, A.Y. (2006). Manufacture of Yoghurt. In Fermented Milks. A. Y. Tamime (ed.), pp. 53-75, Oxford, UK, Blackwell Science Ltd. ISBN 0-632-06458-7

https://doi.org/10.1002/9780470995501.ch3

Tarakçı, Z. (2010). Influence of kiwi marmalade on the rheology characteristics, color values and sensorial acceptability of fruit yogurt. Kafkas Universitesi Veteriner Fakültesi Dergisi, 16(2), 173-178. 